\section{New British Society of Gastroenterology (BSG) guidelines for the diagnosis and management of Barrett's oesophagus}

\section{R J Playford}

The main changes in the recommended guidelines for the management of Barrett's oesophagus by the British Society of Gastroenterology are highlighted, together with their value in the context of the numerous other guidelines and manuscripts that are already available

$\mathrm{T}$ he working party of the BSG has recently produced a document updating recommended guidelines for the management of Barrett's oesophagus (BO). ${ }^{1}$ In this article, the main changes in recommendations are highlighted and their value in the context of the numerous other guidelines and manuscripts that are already available are discussed.

The two key "new" recommendations are

(1) BO is defined as an endoscopically apparent area above the oesophagogastric junction that is suggestive of Barrett's which is supported by the finding of columnar lined oesophagus on histology. The presence of areas of intestinal metaplasia (IM), although often present, is not a requirement for diagnosis

(2) For patients with BO but without dysplasia, the recommended surveillance protocols are two yearly, four quadrant biopsies every $2 \mathrm{~cm}$, but jumbo biopsies are not required.

Additional recommendations include the advice that endoscopic screening of patients suffering from heartburn in order to detect $\mathrm{BO}$ is not recommended and that, in patients with non-dysplastic BO, ablation should be performed only in the context of prospective randomised studies.

The new recommended definition of what constitutes $\mathrm{BO}$ requires a combination of macroscopic and microscopic identification. In the latest definition, in order to have Barrett's mucosa you have to be able to see it with an endoscope. This therefore excludes "ultra-short Barrett's" and also does not require $a \geqslant 3 \mathrm{~cm}$ length (neither of which is likely to generate much controversy). In contrast, histological confirmation still requires the presence of a columnar lined oesophagus but does not require areas of IM to be found. This therefore resembles older style guideline definitions and is out of synchrony with several other current guidelines from other countries. ${ }^{2}$ While it is agreed that adenocarcinoma probably usually originates from a segment containing IM, the rationale behind this decision is that sampling errors at the initial endoscopy may miss an area(s) of IM. Based on a publication, ${ }^{3}$ the guidelines support this decision by their conclusion that "If a sufficient number of biopsies are taken over an adequate period of time, IM can usually be demonstrated (in the majority of these patients)". There is logic in this decision as, using the American guidelines, if a patient has an endoscopy and only areas of CLO without IM are found, by definition, the patient would not have BO and may not be entered into a programme purely due to sampling errors. Nevertheless, this decision may well be a major issue in future meta-analyses and in the acceptance of the generality of clinical research findings obtained from opposite sides of the Atlantic as well as within Europe.

The other major area that is likely to produce heated debate is the advice that, in patients without dysplasia, the appropriate surveillance interval for UK patients is every two years. The advised intervals for surveying patients with $\mathrm{BO}$ without dysplasia in various guidelines have shown marked temporal and regional variations. The current recommendation is based on a new Markovian analysis by a member(s) of the guidelines group. ${ }^{1}$ Unfortunately, details of this analysis are only briefly stated in the document and it has not been published (or peer reviewed) elsewhere. As only minimal data on the assumptions used are provided, this causes real issues with regards to the validity of this decision which will have a major impact on costs and clinical services. In addition to concerns over the validity of this model, there is also the problem that many gastroenterologists have recently spent a large amount of time identifying patients who were "unnecessarily" undergoing annual surveillance and ensuring that they understood the rationale for prolonging to three yearly intervals (including setting up systems and follow up appointments to allow this occur). Is the new data really strong enough to go back and alter these patient pathways?

The current guidelines are a substantial document and provide an excellent overview of BO. For people with a particular interest in $\mathrm{BO}$ this will be a key resource. However, for the general gastroenterologist, it is a somewhat heavy read in order to obtain the key messages highlighted above. As stated in the guidelines, what we really need are new data to answer some of the fundamental questions and this is borne out by the fact that of the 22 principle recommendations, 17 are based only on grade $\mathrm{C}$ (professional opinions) evidence. With regard to this lack of robust data, two developments are worthy of mention. A trial of the use of aspirin prophylaxis to reduce the risk of cancer progression in BO (ASPECT) is currently underway and is likely to provide important answers in a few years' time. ASPECT is also comparing the effect of "normal" $(20 \mathrm{mg})$ and high dose $(80 \mathrm{mg})$ esomeprazole on cancer development. While this second component is of interest, it is severely limited by the failure to include either a "no proton pump inhibitor" or a true "symptom control (as required, PRN)" arm which is what is really required to answer the question "Does acid suppression affect the natural history of BO?".

Because of the protocol being used, the ASPECT study is unlikely to answer many questions regarding the value of surveillance endoscopy. It is therefore timely that the Health Technology Assessment (HTA) group (part of the UK Government Healthcare Commission), who have been considering for several years what questions they would like to examine in the area of $\mathrm{BO}$, are in the process of potentially funding a study on the value of endoscopic surveillance of BO. The cost of performing a full examination of this question however will be expensive (the ASPECT study has cost several million) but it is likely that HTA funding will be limited to around $£ 300000-400000$. As it is generally agreed that this study will require several thousand patients and run for 5-10 years, there is a real danger of it being under resourced. Part of this expenditure is that, if patients are to be 
truly randomised, patients who are entered into the "no surveillance" arm cannot be left to "fend for themselves" and are likely to need regular clinic appointments (which may well not have occurred if they were not in the study) with their associated costs. In the era of full economic costing, approaching centres and asking them to take part without funding support is therefore likely to prove difficult. In addition, while patients on the edge of suitability for surveillance (due to age or coexisting morbidity) are likely to be reasonably happy to take part, the willingness of younger people is likely to be lower and appropriate stratification must be taken into account to allow an answer to the regularly asked question "But what would you do if a 30 year old was found to have BO?". What nobody wants is a trial that will take several years to perform, have low take up, or be dismissed as irrelevant if it is underpowered or confounded. Nevertheless, despite these caveats, it is refreshing to see that there appears to be a realisation that new solid data must be obtained if the old cyclical arguments between advocates and sceptics of the value of routine surveillance of BO is to be resolved. Watch this space (lumen)...

Gut 2006;55:442-443.

doi: 10.1136/gut.2005.083600

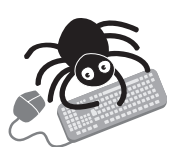

Conflict of interest: declared (the declaration can be viewed on the Gut website at http://www.gutinl.com/supplemental).
Correspondence to: Professor R J Playford, Department of Gastroenterology, Imperial College Faculty of Medicine, Hammersmith Hospital, Ducane Rd, London W12 ONN, UK; r.playford@imperial.ac.uk

\section{REFERENCES}

1 Guidelines for the diagnosis and management of Barrett's columnar lined oesophagus. A report of the working party of the British Society of Gastroenterology. http://www.bsg.org.uk (accessed 17 January 2006).

2 Sampliner RE. Practice guidelines on the diagnosis, surveillance, and therapy of Barrett's esophagus. The Practice Parameters Committee of the American College of Gastroenterology. Am J Gastroenterol 1998;93:1028-32.

3 Shepherd NA. Biddlestone LR. The histopathology and cytopathology of Barrett's oesophagus. In, Manek S, eds. CPD bulletin cellular pathology London, Rila Publications, 1999:39-44.

\section{EDITOR'S QUIZ: GI SNAPSHOT}

\section{Chronic abdominal pain aggravated by eating: diagnosis by video capsule endoscopy}

\section{Clinical presentation}

A 48 year old man presented with a two year history of abdominal pain aggravated by eating, weight loss of $20 \mathrm{~kg}$ in one year, and a positive test for occult blood in stool. In order to avoid postprandial tenesmus he had cut down his meals to a minimum, despite a normal appetite. The patient had no history of previous surgery or serious illness. On physical examination the abdomen was soft and no mass was palpable.

Laboratory examinations did not reveal any pathological findings. On abdominal computed tomography, several fatty structures with a size of $1.5 \mathrm{~cm}$ in apparent continuity with the bowel wall were seen. Abdominal ultrasound, computer tomography of the pancreas, and repeated gastroscopy and colonoscopy did not yield findings that were able to explain the patient's complaints.

\section{Question}

Video capsule endoscopy of the small bowel was performed (fig 1). What abnormalities were seen? What is the likely diagnosis?

See page 497 for answer

This case is submitted by:

F Stenschke, A Nemetz, H Dancygier Klinikum Offenbach, Department of Internal Medicine II, JW Goethe University, Frankfurt am Main, Germany

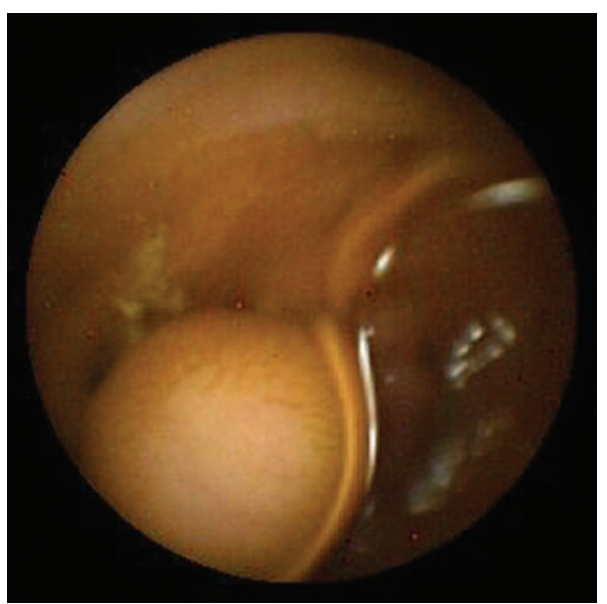

Figure 1 Video capsule endoscopy (Given Imaging Ltd) of the jejunum.

Correspondence to: Dr F Stenschke, Klinikum Offenbach, Department of Internal Medicine II, Starkenburgring 66, D-63069 Offenbach, Germany; frank.stenschke@klinikum-offenbach.de

doi: $10.1136 /$ gut.2005.069823 

the NKG2D receptor, which can interact with MICA thus enabling direct lym-

\section{Interleukin 15: its role in intestinal inflammation}

\section{A van Heel}

Interleukin 15 may have a central role in diverse intestinal inflammatory diseases, such as coeliac disease and inflammatory bowel disease, and hence manipulation of the IL-15 pathway may have therapeutic possibilities in these conditions

$\mathrm{T}$ he cytokine interleukin 15 (IL-15, a protein of 114 amino acids) was first discovered due to IL-2-like stimulatory actions on T cells. ${ }^{12}$ The heterotrimeric IL-15 receptor comprises the $\beta$ and $\gamma$ chains of the IL-2 receptor, with a unique $\alpha$ subunit. These shared receptor subunits most likely explain the similar $\mathrm{T}$ cell growth factor properties of both IL-2 and IL-15. Several cell types can produce IL-15, including macrophages, dendritic cells, and intestinal epithelial cells. The discovery that enterocytes can both produce and respond to IL-15, ${ }^{3}$ and that IL-15 potently stimulates intraepithelial lymphocytes, ${ }^{4}$ has focused attention on its role in intestinal inflammation. IL-15 also has a number of other activities, including recruitment and activation of $\mathrm{T}$ cells, maintenance of $\mathrm{T}$ cell memory, stimulation of proliferation and immunoglobulin synthesis by B cells, natural killer (NK) cell proliferation, activation of neutrophils, and inhibition of apoptosis. Mice with a genetically disrupted IL-15 gene ("knockout") remain healthy under specific pathogen free conditions. ${ }^{5}$ However, they display marked reductions in numbers of thymic and peripheral NK T cells, memory phenotype $\mathrm{CD}^{+} \mathrm{T}$ cells, and distinct subpopulations of intestinal intraepithelial lymphocytes. IL-15 receptor deficient mice demonstrate a broadly similar phenotype. ${ }^{6}$ These defects are rescued in the IL-15 knockout mouse by exogenous IL-15 administration, and IL-15 is therefore critical to the development of these lymphoid lineages.

In inflammatory bowel disease, increased expression of IL-15 on peripheral blood leucocytes has been reported. ${ }^{7}$ Expression of IL-15 mRNA was found to be significantly increased in inflamed rectal mucosa of inflammatory bowel disease patients. ${ }^{8}$ IL- 15 is produced by activated lamina propria macrophages in ileal biopsies from Crohn's disease patients and colonic biopsies from ulcerative colitis patients. ${ }^{9}$ Some care does need to be taken in the interpretation of IL-15 studies, as regulation is mainly at the post-transcriptional level (rather than mRNA) and IL-15 is bioactive in both secreted and membrane-bound forms. Yoshihara and colleagues ${ }^{10}$, in a recent issue of Gut, studied dextran sulphate sodium (DSS) induced colitis, in both acute and chronic phases, in IL-15 knockout and control mice. ${ }^{10}$ In acute colitis $(\sim$ l week DSS), IL-15 knockout mice displayed lower lethality, weight loss, and clinical and histological scores. Knockout mice had reduced lamina propria $\mathrm{CD} 8^{+} \mathrm{T}$ cells and NK cells, and lower levels of lamina propria proinflammatory cytokines (interferon $\gamma$, tumour necrosis factor $\alpha$, and IL-12p40). Similar findings were seen in a chronic colitis model when DSS was given intermittently over 30 days. These data suggest targeting of IL-15 may be a novel therapeutic mechanism in inflammatory bowel disease.

In coeliac disease, IL-15 is also critical in disease pathogenesis, and its role is much better understood. IL-15 is overexpressed in both the lamina propria and intestinal epithelium of patients with active untreated coeliac disease compared with controls and gluten free diet treated coeliac patients. ${ }^{11}$ Mention and colleagues ${ }^{11}$ found that IL-15 was presented at the enterocyte cell surface, rather than being secreted in coeliac disease, suggesting a role in regulating intraepithelial lymphocytes through cell-cell contact. In ex vivo cultured duodenal biopsies, IL-15 mimics most of the epithelial modifications induced by wheat gliadin in coeliac but not in control samples. ${ }^{12}$ Recent work has suggested that a wheat gliadin peptide (A-gliadin p31-43 or p31-49), different to that recognised by $\mathrm{T}$ cells, might act directly to induce IL-15 production in the lamina propria and initiate epithelial apoptosis. ${ }^{13}$ This peptide induces expression of the stress molecule MICA on enterocytes, an effect mediated by IL-15. ${ }^{14}$ IL-15 also activates intraepithelial phocyte mediated cytotoxicity to enterocytes. ${ }^{15} 16$

Di Sabatino and colleagues, ${ }^{17}$ in this issue of Gut, confirm previous studies and extend our knowledge of IL-15 in coeliac disease (see page 469). IL-15 was expressed in untreated coeliac disease enterocytes and lamina propria mononuclear cells, but not in cells from treated coeliacs or healthy patients. Levels correlated with the degree of mucosal damage. Intraepithelial lymphocytes from untreated coeliac patients showed increased activation and granzyme/perforin dependent cytotoxicity against epithelial cells, and resistance to IL-15 induced apoptosis. Enhanced intraepithelial lymphocyte proliferation and apoptosis resistance might be responsible for the generation of $\mathrm{T}$ cell lymphoma in the coeliac disease mucosa. In contrast with previous studies (which used cell line monolayers), Sabatino et al found that IL-15 was secreted by primary human coeliac disease enterocytes as well as being presented on the cell surface. Overexpression of IL-15, specifically in intestinal epithelial cells, in a murine model has been shown to induce chronic inflammation limited to the small intestine, with a histological picture of villous atrophy and lamina propria lymphocyte infiltration. ${ }^{18}$ The lymphocyte infiltrate comprised mostly $\mathrm{CD}^{+} \mathrm{T}$ cells expressing an $\mathrm{NK}$ cell marker, which were resistant to activation induced cell death. ${ }^{18}$ Interestingly, human in vivo data has shown direct mucosal damage when wheat gliadin p31-49 peptide is instilled into the small intestine of patients with coeliac disease. ${ }^{19}$ Further research is necessary to understand the mechanisms of p31-49 signalling and its effects on intestinal mucosa, how this is linked to IL-15 production, and why these changes should only occur in coeliac disease.

A human monoclonal antibody targeting IL-15 (HuMax-IL15, Genmab) has been developed which blocks the epitope of IL- 15 binding to the $\gamma$ subunit of the IL15 receptor. In a phase I/II clinical trial in rheumatoid arthritis, HuMax-IL15 was well tolerated with substantial improvements in disease activity. ${ }^{20}$ These studies suggest that manipulation of the IL-15 pathway might have therapeutic possibilities in both coeliac disease and inflammatory bowel disease. IL-15 appears to be central to coeliac disease, and probably inflammatory bowel disease pathogenesis, and greater understanding of its role is likely to generate further insights into the underlying mechanisms of intestinal inflammation. 


\section{ACKNOWLEDGEMENTS}

$\mathrm{DAvH}$ is supported by grants from the Wellcome Trust, Coeliac UK, and Hammersmith Hospitals Charitable Trustees.

Gut 2006;55:444-445

doi: $10.1136 /$ gut.2005.079335

Correspondence to: Dr David van Heel, Gastroenterology Section, Imperial College London (Hammersmith Campus), Du Cane Road, London W12 ONN, UK; d.vanheel@ imperial.ac.uk

Conflict of interest: None declared.

\section{REFERENCES}

1 Burton JD, Bamford RN, Peters C, et al. A lymphokine, provisionally designated interleukin $T$ and produced by a human adult T-cell leukemia line, stimulates T-cell proliferation and the induction of lymphokine-activated killer cells. Proc Natl Acad Sci U S A 1994;91:4935-9.

2 Carson WE, Giri JG, Lindemann MJ, et al Interleukin (IL) 15 is a novel cytokine that activates human natural killer cells via components of the IL2 receptor. J Exp Med 1994; 180:1395-403

3 Reinecker HC, MacDermott RP, Mirau S, et al Intestinal epithelial cells both express and respond to interleukin 15. Gastroenterology 1996;111:1706-13.
4 Ebert EC. Interleukin 15 is a potent stimulant of intraepithelial lymphocytes. Gastroenterology 1998;115:1439-45.

5 Kennedy MK, Glaccum M, Brown SN, et al. Reversible defects in natural killer and memory CD8 T cell lineages in interleukin 15-deficient mice. J Exp Med 2000;191:771-80.

6 Lodolce JP, Boone DL, Chai S, et al. IL-15 receptor maintains lymphoid homeostasis by supporting lymphocyte homing and proliferation. Immunity 1998;9:669-76.

7 Kirman I, Nielsen $\mathrm{OH}$. Increased numbers of interleukin-15-expressing cells in active ulcerative colitis. Am J Gastroenterol 1996;91:1789-94.

8 Sakai T, Kusugami K, Nishimura H, et al. Interleukin 15 activity in the rectal mucosa of inflammatory bowel disease. Gastroenterology 1998; 114:1237-43.

9 Liu Z, Geboes K, Colpaert S, et al. IL-15 is highly expressed in inflammatory bowel disease and regulates local T cell-dependent cytokine production. J Immunol 2000; 164:3608-15.

10 Yoshihara K, Yaijima T, Kubo C, et al. The role of interleukin 15 in colitis induced by dextran sulphate sodium in mice. Gut 2006;55:334-41.

11 Mention JJ, Ben Ahmed M, Begue B, et al. Interleukin 15: a key to disrupted intraepithelial lymphocyte homeostasis and lymphomagenesis in celiac disease. Gastroenterology 2003; 125:730-45.

12 Maiuri L, Ciacci C, Auricchio S, et al. Interleukin 15 mediates epithelial changes in celiac disease. Gastroenterology 2000;119:996-1006.
13 Maiuri L, Ciacci C, Ricciardelli I, et al. Association between innate response to gliadin and activation of pathogenic T cells in coeliac disease. Lancet 2003:362:30-7.

14 Hue S, Mention JJ, Monteiro RC, et al. A direct role for NKG2D/MICA interaction in villous atrophy during celiac disease. Immunity 2004;21:367-77.

15 Meresse B, Chen Z, Ciszewski C et al. Coordinated induction by IL 15 of a TCR independent NKG2D signaling pathway converts CTL into lymphokine-activated killer cells in celiac disease. Immunity 2004;21:357-66.

16 Kinoshita N, Hiroi T, Ohta N, et al. Autocrine IL15 mediates intestinal epithelial cell death via the activation of neighboring intraepithelial NK cells. $\mathrm{J}$ Immunol 2002;169:6187-92.

17 Di Sabatino A, Ciccocioppo R, Cupelli F, et al. Epithelium derived interleukin 15 regulates intraepithelial lymphocyte Th1 cytokine production, cytotoxicity, and survival in coeliac disease. Gut 2006:55:469-77.

18 Ohta N, Hiroi T, Kweon MN, et al. IL-15dependent activation-induced cell death-resistant Th1 type CD8 alpha beta+NK1.1+ T cells for the development of small intestinal inflammation. $\mathrm{J}$ Immunol 2002; 169:460-8.

19 Sturgess R, Day P, Ellis HJ, et al. Wheat peptide challenge in coeliac disease. Lancet 1994;343:758-61.

20 Baslund B, Trede N, Danneskiold-Samsoe B et al. Targeting interleukin-15 in patients with rheumatoid arthritis: A proof-of-concept study. Arthritis Rheum 2005;52:2686-92.

factor in these two disorders..$^{5-8}$ Histamine is not expressed by enteric neurones and is not a neurotransmitter in the ENS. ${ }^{9}$ Its signalling function is paracrine in nature through release from enteric mast cells and inflammatory granulocytes. Mastocytosis and presumably elevated availability of histamine are present in microscopic colitis, parasitic infections, IBS, and no doubt additional functional gastrointestinal disorders associated with symptoms of cramping abdominal pain, watery diarrhoea, and defecation urgency. ${ }^{6} 810-17$

There is altered expression of histamine $\mathrm{H}_{1}$ and $\mathrm{H}_{2}$ receptor subtypes in mucosal biopsies from the terminal ileum and large intestine of patients with symptoms of food allergy and/or irritable bowel syndrome

$\mathrm{T}$ he research article by Sander and colleagues $^{1}$ in this issue of Gut, reports their results for expression of histamine receptor subtypes in the human intestinal tract from normal individuals and patients with symptoms of the irritable bowel syndrome (IBS) and/or food allergies (see page 498). Work of this nature was overdue because most of the available histological and functional data for histamine receptors in the small and large intestine were obtained from animal models. The authors' principal findings for the human bowel are in general agreement with the animal literature that reports on expression of the histamine $\mathrm{H}_{1}, \mathrm{H}_{2}$, and $\mathrm{H}_{4}$ receptor subtypes in the enteric nervous system (ENS), intestinal musculature, mucosal epithelium, and

immune/inflammatory cells. In contrast, the finding by Sander and colleagues ${ }^{1}$ that histamine $\mathrm{H}_{3}$ receptors are not expressed in the human bowel was unexpected in view of the clearcut evidence for functional involvement of the $\mathrm{H}_{3}$ receptor subtype in the nervous control of motility, secretion, and blood flow in guinea pig intestine, which serves as the primary animal model. ${ }^{2-5}$

The authors' evidence for altered expression of histamine $\mathrm{H}_{1}$ and $\mathrm{H}_{2}$ receptor subtypes in mucosal biopsies from the terminal ileum and large intestine of patients with symptoms of food allergy and/or IBS is consistent with current concepts for the involvement of histamine release from enteric mast cells and its paracrine signalling function in the ENS as an underlying
The appearance of histamine $\mathrm{H}_{2}$ receptors in human myenteric ganglia is reminiscent of expression of the $\mathrm{H}_{2}$ receptor subtype in the guinea pig ENS. Binding of histamine to $\mathrm{H}_{2}$ receptors on enteric neuronal cell bodies in the guinea pig, either during exogenous application of histamine or by degranulation of neighbouring mast cells, elevates neuronal excitability characterised by firing of longlasting trains of nerve impulses. ${ }^{18-21}$ In the case of submucosal secretomotor neurones, elevated firing rates increase the volume of mucosal secretions of electrolytes and $\mathrm{H}_{2} \mathrm{O}$ and thereby increase the liquidity of the intestinal contents, which in turn can underlie neurogenic secretory diarrhoea. ${ }^{22}$ For musculomotor neurones in the myenteric plexus, histamine $\mathrm{H}_{2}$ evoked firing alters contractile behaviour of the muscularis externa that is coordinated with organised secretory patterns. $^{23}$ Similar outcomes for 
release of histamine and its actions at the $\mathrm{H}_{2}$ neuronal receptors, now reported by Sander and colleagues ${ }^{1}$ for human ENS, can be reasonably assumed Nevertheless, progress in understanding specific pathophysiological malfunctions and therapeutic improvisation requires that future human research be pursued along the lines of what has been done in basic science models.

Excitation of ENS neuronal perikarya is one of the significant actions of histamine at the $\mathrm{H}_{2}$ receptor subtype. A second important action, which has been well documented in the guinea pig enteric ENS but not in humans, is suppression of synaptic transmission. $^{21925}$ Exposure of the ENS to histamine, either by exogenous application in vitro or by release from sensitised mast cells in response to allergins (for example, food proteins or infectious organisms), suppresses neurotransmitter release at four important information transmission nodes in the neural microcircuitry. Which are: (1) fast excitatory nicotinic synapses; (2) slow excitatory synapses where serotonin, substance $\mathrm{P}$, calcitonin gene related peptide, and ATP are among the putative neurotransmitters; (3) slow inhibitory synapses, especially on submucosal secretomotor neurones, where norepinephrine release from the sympathetic innervation and somatostatin released from intrinsic neurons are inhibitory neurotransmitters; and (4) sympathetic neurovascular junctions.

Inhibition of neurotransmission in each of these cases is presynaptic. Stimulation of presynaptic inhibitory receptors by histamine suppresses the release of neurotransmitter from the presynaptic axonal terminal and thereby inhibits transmission of neural signals. Inhibition of transmission at the multitude of nicotinic synapses in the enteric neural networks would be expected to prevent "call-up" of selective behavioural programmes or to selectively activate a specific programme in the ENS library of programmes (for example, intestinal defence). ${ }^{5}$ Suppression of slow excitatory transmission, either at selective slow synapses or in combination with suppression of fast nicotinic transmission, is probably also involved in generation of the pattern of defensive intestinal behaviour, which can be demonstrated during exposure to sensitising antigens in previously sensitised animals. Slow inhibitory postsynaptic potentials (IPSPs) in submucosal secretomotor neurones impose a braking action on neurogenic secretion that is removed when histamine is applied experimentally or released from enteric mast cells in sensitised animals. Removal of the sympathetic brake from secretomotor neurones is a factor underlying the diarrhoeal states associated with allergic responses and mucosal inflammation. ${ }^{2}$ Suppression of norepinephrine release at submucosal neurovascular junctions removes the sympathetic braking action on blood flow, which in effect supports stimulation of neurogenic mucosal secretion. ${ }^{4}$

Several types of presynaptic inhibitory receptors are expressed in the ENS, one of which is a histaminergic receptor. The presynaptic histaminergic inhibitory receptor in the guinea pig ENS belongs to the histamine $\mathrm{H}_{3}$ receptor subtype. The slow IPSPs in guinea pig secretomotor neurones, which are mediated by release of norepinephrine and somatostatin, are suppressed by histamine. ${ }^{2}$ Selective histamine $\mathrm{H}_{3}$ agonists, but not histamine $\mathrm{H}_{1}$ or $\mathrm{H}_{2}$ agonists, act presynaptically to suppress IPSPs, and selective $\mathrm{H}_{3}$ antagonists, but not $\mathrm{H}_{1}$ or $\mathrm{H}_{2}$ antagonists, block both the effects of exogenously applied histamine and the effects of histamine released from mast cells in sensitised animal preparations. ${ }^{219-21} 25$ Likewise, suppression of excitatory neurotransmission at other neural synapses and neurovascular junctions reflects histamine $\mathrm{H}_{3}$ mediated inhibition of neurotransmitter release. $^{4}$

Absence of the histamine $\mathrm{H}_{3}$ receptor subtype from human bowel, as reported by Sander and colleagues, ${ }^{1}$ was unexpected and is paradoxical in view of the evidence in the literature for its expression and importance in the animal model. Data to explain the paradox are not readily available. On the one hand, failure to find the human receptor with any of three valid methods (that is, immunohistochemistry, western blot, or reverse transcription-polymerase chain reaction) strongly supports the conclusion that the $\mathrm{H}_{3}$ receptor is not expressed in human bowel. On the other hand, evidence from physiological studies convincingly supports expression and important functional significance of the receptor in the guinea pig model. This is a dilemma raised by Sander and colleagues. ${ }^{1}$

The importance of histamine release from enteric mast cells in terms of intestinal symptoms, which are associated with human allergy, IBS and brain-gut interactions in stress is widely supported and convincing. ${ }^{12-15} 26$ Symptoms of watery diarrhoea, urgency, cramping abdominal pain, and intestinal hypersensitivity to distension in humans appear in general to have a counterpart in animal models, whether it is a guinea pig, rat, or canine model. ${ }^{5}{ }^{6}$ These symptoms are perceived as side effects of the "running" of a specific ENS neural programme that has evolved as a defensive mechanism for rapid expulsion from the intestine of a threat to the integrity of the whole animal. If this is indeed the case, then the mechanisms of histaminergic call-up of programmed intestinal defence are not expected to differ much across mammalian species. Most of the results reported by Sander and colleagues ${ }^{1}$ are consistent with this concept, except for the absence of the histamine $\mathrm{H}_{3}$ receptor subtype. Histaminergic presynaptic inhibition that removes the sympathetic brake on secretion and mucosal blood flow would seem to be a necessary requirement in the "running" of the secretory component of the neural defence programme that "flushes" threatening agents and organisms from the mucosa and maintains them in suspension in a fluid filled intestine awaiting clearance by powerful propulsive motility.

In view of the importance of immune/ inflammatory cells and histamine signalling in the ENS, thorough understanding for the human gut is imperative. A credible start in this direction has been made by Sander and colleagues. ${ }^{1}$ Now, neurogastroenterological research must determine whether presynaptic inhibition in the ENS has the same significance for the common symptoms of food allergy, mucosal inflammation, and brain-gut interactions in stress in humans, as is known to exist in animal models. If this proves to be the case, then additional investigation will be needed to determine if it might be mediated by a histamine receptor other than the $\mathrm{H}_{3}$ subtype.

Gut 2006;55:445-447.

doi: 10.1136/gut.2005.079046

Correspondence to: Professor J D Wood,

Department of Physiology and Cell Biology, The Ohio State University College of Medicine, 304 Hamilton Hall, 1645 Neil Ave, Columbus, Ohio 43210-1218, USA; wood.13@osu.edu

Conflict of interest: None declared.

\section{REFERENCES}

1 Sander LE, Lorentz A, Sellge G, et al. Selective expression of histamine receptors $\mathrm{H} 1 \mathrm{R}, \mathrm{H} 2 \mathrm{R}$, and $\mathrm{H} 4 \mathrm{R}$, but not $\mathrm{H} 3 \mathrm{R}$, in the human intestinal tract. Gut 2006;55:498-504.

2 Liv S, Xia Y, Hu H-Z, et al. Histamine $\mathrm{H}_{3}$ receptormediated suppression of inhibitory synaptic transmission in the guinea-pig submucous plexus. Eur J Pharmacol 2000;397:49-54.

3 Blandizzi C, Tognetti M, Colucci R, et al. Histamine $H(3)$ receptors mediate inhibition of noradrenaline release from intestinal sympathetic nerves. Br J Pharmacol 2000;129:1387-96.

4 Ishikawa S, Sperelakis N. A novel class $(\mathrm{H} 3)$ of histamine receptors on perivascular nerve terminals. Nature 1987;327:158-60.

5 Wood JD. Enteric neuroimmuno physiology and pathophysiology. Gastroenterology 2004; 127:635-57.

6 Wood JD. Neuro-pathophysiology of IBS. J Clin Gastroenterol 2002;35(suppl):11-22.

7 Barbara G, De Giorgio R, Stanghellini V, et al. New pathophysiological mechanisms in irritable 
bowel syndrome. Aliment Pharmacol Ther 2004;20(suppl 2):1-9.

8 Barbara G, Stanghellini V, De Giorgio R, et al. Activated mast cells in proximity to colonic nerves correlate with abdominal pain in irritable bowel syndrome. Gastroenterology 2004; 126:693-702.

9 Panula P, Kaartinen M, Macklin M, et al. Histamine-containing peripheral neuronal and endocrine systems. J Histochem Cytochem 1985;33:933-41.

10 O'Sullivan M, Clayton N, Breslin NP, et al. Increased mast cells in the irritable bowel syndrome. Neurogastroenterol Motil 2000; 12:449-57.

11 Baum CA, Bhatia P, Miner PB Jr. Increased colonic mucosal mast cells associated with severe watery diarrhea and microscopic colitis. Dig Dis Sci 1989;34: 1462-5.

12 Siddiqui AA, Miner PB Jr. The role of mast cells in common gastrointestinal diseases. Curr Allergy Asthma Rep 2004;4:47-54.

13 Weston AP, Biddle WL, Bhatia PS, et al. Terminal ileal mucosal mast cells in irritable bowel syndrome. Dig Dis Sci 1993;38:1590-5.
14 Libel R, Biddle WL, Miner PB Jr. Evaluation of anorectal physiology in patients with increased mast cells. Dig Dis Sci 1993;38:877-81.

15 Miner PB Jr. The role of the mast cell in clinical gastrointestinal disease with special reference to systemic mastocytosis. J Invest Dermatol 1991:96:40-3S.

16 Russell DA, Castro GA. Immunological regulation of colonic ion transport. Am J Physiol 1989;256:G396-403.

17 Alizadeh H, Castro GA, Weems WA. Intrinsic jejunal propulsion in the guinea pig during parasitism with Trichinella spiralis. Gastroenterology 1987;93:784-90.

18 Nemeth PR, Ort CA, Wood JD. Intracellular study of effects of histamine on electrical behaviour of myenteric neurones in guinea-pig small intestine. J Physiol 1984;355:41 1-25.

19 Frieling T, Cooke HJ, Wood JD. Histamine receptors on submucous neurons in guinea pig colon. Am J Physiol 1993;264:G74-80.

20 Frieling T, Cooke HJ, Wood JD. Neuroimmune communication in the submucous plexus of guinea pig colon after sensitization to milk antigen. Am J Physiol 1994;267:G1087-93.
21 Frieling T, Palmer JM, Cooke $\mathrm{HJ}$, et al Neuroimmune communication in the submucous plexus of guinea pig colon after infection with Trichinella spiralis. Gastroenterology 1994; 107:1602-9.

22 Cooke HJ. Neurotransmitters in neuronal reflexes regulating intestinal secretion. Ann N Y Acad Sci 2000;915:77-80.

23 Cooke HJ, Wang YZ, Rogers R. Coordination of $\mathrm{Cl}^{-}$secretion and contraction by a histamine $\mathrm{H}_{2}$ receptor agonist in guinea pig distal colon. Am J Physiol 1993:265:G973-8.

24 Bozarov AV, Wang Y-Z, Javed N, et al. New method to study coordination of secretory and motility reflexes using sonomicrometry and voltage clamp apparatus in flat intestinal sheets. Gastroenterology 2005;128(suppl 2):A608.

25 Tamura K, Palmer JM, Wood JD. Presynaptic inhibition produced by histamine at nicotinic synapses in enteric ganglia. Neuroscience 1988:25:171-9.

26 Santos J, Saperas E, Nogueiras C, Malagelada $\mathrm{JR}$, et al. Release of mast cell mediators into the jejunum by cold pain stress in humans. Gastroenterology 1998;114:640-8.

\section{Crohn's disease: why the disparity in mortality?}

\section{E V Loffus Jr}

\section{There has been no significant decrease in mortality in patients with Crohn's disease over the last several decades}

lis. is well accepted that Crohn's disease is associated with a small but real risk of death. Population based reports from Sweden, ${ }^{12}$ Denmark, ${ }^{3}$ and Italy ${ }^{4}$ indicate that Crohn's disease patients have a higher mortality rate than expected, although at least one notable exception from the UK demonstrated survival similar to the general population (table 1). ${ }^{5}$ A preliminary report from Olmsted County, Minnesota, indicated a mortality rate that was about $20 \%$ higher (but not significantly different statistically) than that expected, standing in contrast with the results of a previous report from the same location. ${ }^{7}$ The largest study of mortality in Crohn's disease was from a cohort of approximately 6000 patients identified through the General Practice Research Database (GPRD), which contains the computerised medical records of $6 \%$ of the British population. ${ }^{8}$ The annual mortality rate in Crohn's disease was $1.6 \%$ compared with $1.0 \%$ in age, sex, and practice matched controls. After adjusting for age, sex, and cigarette smoking, it appeared that the risk of death was $73 \%$ higher in Crohn's disease patients than in controls. ${ }^{8}$ Although the large cohort size makes this study important, its generalisability is limited by the fact that the cohort was a mixture of incidence and prevalence cases, the average age at entry into the cohort was 42 years (higher than the average age at diagnosis of Crohn's disease of late 20s/early 30s in most studies), and the average follow up was only three years. A recent systematic review of "hard end points" in population based cohorts of Crohn's disease concluded that there was no evidence for a significant change in disease outcome over the past 40 years. ${ }^{9}$ To summarise, these studies suggest that the mortality rate in Crohn's disease ranges from $30 \%$ lower than expected to $70 \%$ higher than expected. All of these studies are limited by the fact that most of the patients in these cohorts were not only identified retrospectively, but also diagnosed before the "modern era" of medical therapy for Crohn's disease.

The European Collaborative Study Group of Inflammatory Bowel Disease (EC-IBD) prospectively developed a cohort of patients newly diagnosed with Crohn's disease and ulcerative colitis at 20 European and Israeli centres between October 1991 and September 1993. The incidence of Crohn's disease at these centres over this two year period ${ }^{10}$ and the clinical course in these patients in the first year after diagnosis ${ }^{11}$ have been previously reported. In the present issue of Gut, Wolters and colleagues ${ }^{12}$ update the follow up of approximately half of the original EC-IBD cohort of Crohn's disease patients $(n=371)$ to determine absolute, relative, and cause specific mortality (see page 510). Median age at diagnosis of Crohn's disease was 31 years (range 15-83). Follow up was complete in $92 \%$ of the cohort. After an average follow up of approximately 10 years, 37 patients had died $(10 \%)$. Expected rates of death were calculated using country, age, and sex specific rates from the World Health Organisation (WHO) mortality database. Using actuarial techniques, the 10 year risk of death was $10 \%$ versus $7 \%$ expected. One would have expected 21 patients to have died based on the WHO mortality rates. The standardised mortality ratio (SMR, which can be thought of as a relative mortality rate) was 1.85 , or $85 \%$ higher than expected.

The authors examined their cohort for risk factors. For both sexes, SMR was significantly higher than expected..$^{12}$ The relative risk of death was numerically higher in the northern European centres (SMR 2.0 (95\% confidence interval (CI) 1.3-3.0)) than in southern ones (SMR $1.6(95 \%$ CI $0.8-2.7))$ but this difference was not statistically significant. When the SMR analysis was stratified by various aspects of the phenotypic Vienna classification, ${ }^{13}$ age $\geqslant 40$ years at diagnosis (SMR 1.99 (95\% CI, 1.4$2.8)$ ), colonic involvement at diagnosis (SMR $2.1 \quad$ (95\% CI $1.3-3.1)$ ), and inflammatory disease behaviour at diagnosis (SMR 2.2 (95\% CI, 1.5-3.2)) all appeared to be associated with increased mortality risk. However, in a multivariate 
Table 1 Crohn's disease related mortality from selected population-based cohorts published since 1992

\begin{tabular}{|c|c|c|c|c|c|c|}
\hline $\begin{array}{l}\text { Author } \\
\text { (ref) }\end{array}$ & Location & Cohort type & $\begin{array}{l}\text { Study } \\
\text { period }\end{array}$ & No & $\begin{array}{l}\text { Median or } \\
\text { mean follow } \\
\text { up (y) }\end{array}$ & $\begin{array}{l}\text { Overall SMR } \\
(95 \% \mathrm{Cl})\end{array}$ \\
\hline Ekbom' & $\begin{array}{l}\text { Uppsala, } \\
\text { Sweden }\end{array}$ & $\begin{array}{l}\text { Incidence (89\%) } \\
\text { and prevalence } \\
(11 \%)\end{array}$ & $1965-83$ & 1655 & NA & $1.6(1.4-1.9)$ \\
\hline Probert $^{5}$ & Leicestershire, UK & Incidence & $1972-89$ & 610 & NA & $0.7(0.5-1.0)$ \\
\hline Persson ${ }^{2}$ & $\begin{array}{l}\text { Stockholm } \\
\text { County, Sweden }\end{array}$ & Incidence & $1955-84$ & 1251 & NA & $1.5(1.3-1.7)$ \\
\hline Jess $^{3}$ & $\begin{array}{l}\text { Copenhagen } \\
\text { County, Denmark }\end{array}$ & Incidence & $1962-87$ & 374 & 17 & $1.3(1.0-1.6)$ \\
\hline $\operatorname{Card}^{8}$ & GPRD, UK & $\begin{array}{l}\text { Incidence (31\%) } \\
\text { and prevalence } \\
(69 \%)\end{array}$ & 1987-?? & 5960 & 3.6 & $1.7(1.5-2.0)$ \\
\hline Masala $^{4}$ & Florence, Italy & Incidence & $1978-92$ & 231 & 15.4 & $1.5(1.1-2.1)$ \\
\hline Jess $^{6}$ & $\begin{array}{l}\text { Olmsted County, } \\
\text { USA }\end{array}$ & Incidence & 1940-2001 & 314 & 13 & $1.2(0.9-1.6)$ \\
\hline Wolters $^{12}$ & $\begin{array}{l}\text { EC-IBD, Europe } \\
\text { and Israel }\end{array}$ & Incidence & 1991-93 & 371 & 10 & $1.9(1.3-2.5)$ \\
\hline
\end{tabular}

SMR, standardised morbidity ratio (observed/expected); $95 \% \mathrm{Cl}, 95 \%$ confidence interval; NA, not available; EC-IBD, European Collaborative Study Group of Inflammatory Bowel Disease.

Cox proportional hazards regression analysis, the only independent predictor of mortality was age at diagnosis (hazards ratio per year 1.1 (95\% CI 1.08-1.12)).

Cause specific mortality was also examined. Fourteen deaths $(38 \%$ of all deaths) were thought by the investigators to be definitely or possibly related to Crohn's disease, including eight deaths due to various gastrointestinal causes (for example, postoperative sepsis, toxic megacolon, bowel infarction), two cases of sepsis in patients on corticosteroids, and three deaths due to cardiovascular causes in patients with active Crohn's disease or in the immediate postoperative setting. Among the 23 deaths that were not attributed to Crohn's disease, there were three deaths due to bronchogenic carcinoma, eight due to various cardiovascular conditions such as myocardial infarction or cerebrovascular accident, and three deaths due to pneumonia or chronic obstructive pulmonary disease. These results are somewhat in keeping with other studies that have examined cause specific mortality in Crohn's disease. The percentage of deaths attributed to Crohn's disease ranges from $25 \%$ to $40 \%$. Crohn's disease patients are significantly more likely to die from non-malignant gastrointestinal diseases. ${ }^{1-46}$ In some studies, they were also more likely to die from intestinal cancer $^{36}$ and bronchogenic carcinoma. ${ }^{4}$

The EC-IBD mortality study ${ }^{12}$ has a number of strengths. All cases were from defined geographic regions, newly diagnosed, and prospectively identified. Follow up was complete in greater than $90 \%$. Such studies of population based inception cohorts are the "purest" form of natural history and prognosis studies. Secondly, the subgroup analysis, stratified phenotypically by the Vienna classification, is somewhat novel, even though ultimately disease extent and behaviour were not found to be independent predictors of mortality. Increasing age at diagnosis was significantly associated with mortality, but this is often found in mortality studies of any condition.

Several potential weaknesses of this study deserve comment. Firstly, only 10 of the original 20 EC-IBD centres participated (seven refused outright and the other three could not follow up more than $60 \%$ of their cohort), leaving only 371 of the original 706 Crohn's patients. ${ }^{12}$ It is not known whether mortality among the patients who were not followed is similar to, lower than, or higher than what was observed in this cohort. Did these participating centres have more of an interest in IBD, and thus was the care of patients in these centres somehow different? It is also not clear if similar methods of determining vital status at last follow up were employed-some centres were located in countries with an accessible national death registry while others were not.

While the EC-IBD study provides important information, it raises additional questions. Despite the fact that these patients were diagnosed in the 1990s, an era of more aggressive medical therapy, and despite the fact that follow up in this cohort was only 10 years on average, the authors demonstrated a mortality rate nearly double what had been expected. ${ }^{12}$ Comparing this study to others, there has been no significant decrease in mortality (and perhaps an increase?) in Crohn's disease patients over the last several decades. Why is there a disparity in relative mortality across regions, even in recent studies? In other words, why are the mortality rates only $20-30 \%$ higher than expected in Olmsted or Copenhagen Counties but $70-90 \%$ higher than expected in the GPRD and EC-IBD studies? This disparity is all the more puzzling as 58 members of the EC-IBD cohort were from Copenhagen County, but diagnosed 4-6 years after the latest entry date in the original Copenhagen County study. In the Copenhagen subset of ECIBD patients, SMR was 2.3 (see table 2 of the Wolters and colleagues study ${ }^{12}$ ), considerably higher than the 1.3 seen in the earlier Copenhagen cohort. ${ }^{3}$ Some differences in SMRs across cohorts can be attributed to differences in expected mortality rates, which are dependent on the overall age and gender makeup of the cohort. Another potential explanation for disparity is variation in disease severity. In the EC-IBD study, patients from northern centres were more likely $(31 \%)$ than patients from southern centres $(17 \%)$ to have required azathioprine. ${ }^{12}$ Is this a marker for disease severity or is there a causal relationship between azathioprine use and increased mortality? Most of us would suspect the former, but the observational nature of this study does not permit us to answer the question.

The study by Wolters and colleagues reminds us that Crohn's disease is, in fact, still associated with increased mortality at most centres. Crohn's disease is a chronic progressive illness and should be treated as such. While death due to Crohn's disease occurs too infrequently for it to be incorporated as an end point in clinical trials, we should strive to perform studies with novel designs and "hard end points" (for example, "step up versus top down"14 or SONIC) to determine if earlier or more aggressive medical therapy can alter the natural history of the illness.

Gut 2006;55:447-449.

doi: $10.1136 /$ gut.2005.080283

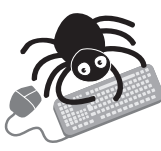

Conflict of interest: declared (the declaration can be viewed on the Gut website at http://www.gutinl.com/supplemental).

Correspondence to: Dr E V Loftus, Jr, Division of Gastroenterology and Hepatology, Mayo Clinic, 200 First Street, SW Rochester, MN 55905, USA; loftus.edward@mayo.edu

\section{REFERENCES}

1 Ekbom A, Helmick CG, Zack M, et al. Survival and causes of death in patients with inflammatory bowel disease: a population-based study. Gastroenterology 1992;103:954-60.

2 Persson PG, Bernell O, Leijonmarck CE, et al. Survival and cause-specific mortality in inflammatory bowel disease: a population-based cohort study. Gastroenterology 1996; 110:1339-45. 


\section{COMMENTARIES}

3 Jess T, Winther KV, Munkholm P, et al. Mortality and causes of death in Crohn's disease: follow-up of a population-based cohort in Copenhagen County, Denmark. Gastroenterology 2002; 122:1808-14

4 Masala G, Bagnoli S, Ceroti M, et al. Divergent patterns of total and cancer mortality in ulcerative colitis and Crohn's disease patients: the Florence IBD study 1978-2001. Gut 2004:53:1309-13.

5 Probert CS, Jayanthi V, Wicks AC, et al. Mortality from Crohn's disease in Leicestershire, 19721989: an epidemiological community based study. Gut 1992;33:1226-8.

6 Jess T, Loftus EV, Harmsen WS, et al. Survival and cause-specific mortality in patients with inflammatory bowel disease. A population-based cohort study, Olmsted County, Minnesota, 19402004 (abstract). Gastroenterology 2005; 128:A321.
7 Loftus EV Jr, Silverstein MD, Sandborn WJ, et al. Crohn's disease in Olmsted County, Minnesota, 1940-1993: incidence, prevalence, and survival. Gastroenterology 1998; 1 14:1161-8.

8 Card T, Hubbard R, Logan RF. Mortality in inflammatory bowel disease: a population-based cohort study. Gastroenterology 2003; 125:1583-90

9 Wolters FL, Russel MG, Stockbrugger RW. Systematic review: has disease outcome in Crohn's disease changed during the last four decades? Aliment Pharmacol Ther 2004;20:483-96.

10 Shivananda S, Lennard-Jones J, Logan R, et al. Incidence of inflammatory bowel disease across Europe: is there a difference between north and south? Results of the European Collaborative Study on Inflammatory Bowel Disease (EC-IBD). Gut 1996:39:690-7.
11 Witte J, Shivananda S, Lennard-Jones JE, et al. Disease outcome in inflammatory bowel disease: Mortality, morbidity and therapeutic management of a 796-person inception cohort in the European Collaborative Study on Inflammatory Bowel Disease (EC-IBD). Scand J Gastroenterol 2000;35:1272-7.

12 Wolters FL, Russel MG, Sijbrandii J, et al. Crohn's disease: increased mortality 10 years after diagnosis in a Europe-wide population based cohort. Gut 2006;55:510-8.

13 Gasche C, Scholmerich J, Brynskov J, et al. A simple classification of Crohn's disease: Report of the Working Party for the world congresses of gastroenterology, Vienna 1998. Inflamm Bowel Dis 2000;6:8-15.

14 Hommes D, Baert F, van Assche G, et al. Management of recent onset Crohn's disease: a controlled, randomized trial comparing step-up and top-down therapy. Gastroenterology 2005; 129:371.

\section{EDITOR'S QUIZ: GI SNAPSHOT}

\section{Answer}

From question on page 441

Abdominal computed tomography scan demonstrated a voluminous right common iliac aneurysm adjacent to the lumen of the sigmoid. Angiography (fig 3) confirmed this, and laparotomy showed a large aneurysm from the right common iliac artery fistulised in the sigmoid which was embedded in the pelvis. A femoral-femoral bypass grafting procedure for revascularising the right limb was completed, the thrombosed aneurysm removed, and a left colectomy without primary anastomosis was performed. Histological examination of the colectomy specimen confirmed the fistula. The patient was discharged to her local hospital on day 30.

Vascular-enteric fistula is a rare but life threatening disease with a very high mortality. The most frequent is aortoduodenal fistula in patients with a history of aortic graft surgery. Aorto-colonic fistula accounts for only approximately $5 \%$ of all reported cases. Most published cases are secondary fistulas after surgical repair of abdominal aortic aneurysm. Only two cases of primary iliac-enteric fistulas involving the ileum or rectum and arising from common iliac aneurysms have been published. Endoscopic findings included the presence of luminal pulsatile mass, puncture ulceration, visualisation of graft materiel, or pulsatile fresh blood. In our case, colonoscopy was very suggestive because the punctate ulceration was associated with a very pulsate appearance. Angiography may not be diagnostic because of the intermittent nature of the bleed but it can show the aneurysm. In the case of undiagnosed lower gastrointestinal bleeding, vascular-enteric fistula must be considered, especially among old people, whether or not there is a background of previous vascular surgery. Early diagnosis and urgent surgery are necessary to improve the prognosis of this very serious disease, with a mortality rate of approximately $30 \%$.

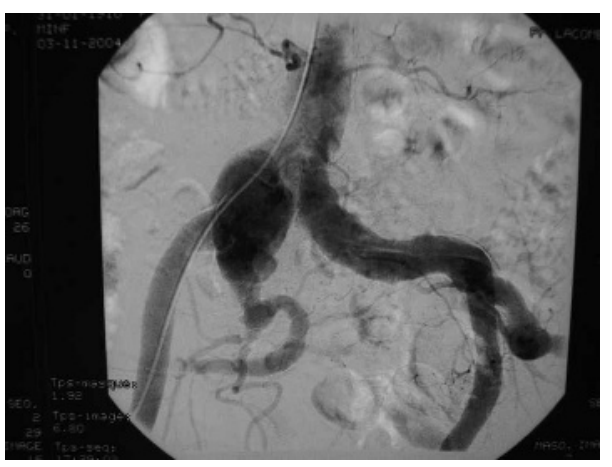

Figure 3 Angiogram showing a large right iliac primary artery aneurysm. 